\title{
DORIT RABINYAN: COMENTÁRIOS E REFLEXÕES \\ ENCONTROS DE LITERATURA HEBRAICA (GRUPO DE LEITURA)
}

\author{
DORIT RABINYAN: COMMENTARIES AND REFLEXIONS \\ HEBREW LITERATURE GATHERINGS (READING GROUP)
}

Eliana Langer, Naamá Silverman Forner e Sara Krengel**

\begin{abstract}
Resumo
Iniciamos este artigo com comentários gerais sobre a atividade de grupos de leitura e sua possível contribuição para a análise e pesquisa literárias. Em seguida, trazemos reflexões de um grupo de leitura que se encontra mensalmente para falar em hebraico sobre obras da literatura hebraica. Dois encontros foram dedicados aos romances $O$ beco das amendoeiras em Omaridjan (1995) e Nossos Casamentos (1999), cuja autora é Dorit Rabinyan. As ideias, abordagens e análises do grupo foram reunidas, editadas e formuladas no texto abaixo. Para finalizar, acrescentamos alguns comentários acerca do último romance da autora, Cerca viva, publicado recentemente (2014).
\end{abstract}

Palavras-chave: Literatura hebraica, Dorit Rabinyan, Grupo de leitura.

\begin{abstract}
This article opens with few theoretical comments on the social phenomenon of reading groups (book clubs) and the possible contribution of their activity to literary analysis and research. Then we bring reflections of our reading group that meets monthly to talk in Hebrew, about Hebrew literature. Two meetings of this group were devoted to the novels "Persian Brides" (or: "Omaridjan") (1995) and "Our Weddings" (1999), by Dorit Rabinyan. Ideas, approaches and analyzes of the group were gathered and edited in the text below. Finally, we add some comments about the last novel of the author, "Borderlife", published in 2014.
\end{abstract}

Keywords: Hebrew Literature, Dorit Rabinyan, reading group

\footnotetext{
* Langer é professora de Língua Hebraica na Universidade de São Paulo. Forner é doutora em Literatura Hebraica pela Universidade de São Paulo. Krengel é mestre em Ciências Humanas pela Universidade de Tel Aviv.
} 
Há mais de dois anos, em São Paulo, o clube de leitores de literatura hebraica iniciou suas atividades. Oito mulheres compõem o grupo atualmente e, durante esse período, foram lidos no original mais de vinte livros, todos de literatura hebraica atual moderna e contemporânea.

A escrita deste artigo nasceu da vontade de compartilhar nossos estudos com quem se interessa pela literatura hebraica e aproximá-la de quem ainda não a conhece. Atualmente, a literatura hebraica tem sido traduzida para o português num ritmo ainda lento. Acreditamos que podemos contribuir com a sua divulgação, compartilhando reflexões e ideias que surgem nas discussões do grupo.

Por que escrever, ou de certa forma documentar a atividade de um grupo independente que se organizou em torno de um tema comum a seus membros e que aparentemente é irrelevante para o público em geral?

Para responder a questão abordaremos dois aspectos: o primeiro, ligado a especificidade desse grupo que se autoimpôs a leitura de tão somente obras originais da literatura hebraica, apesar de não ser a língua materna da maioria de suas integrantes e tampouco a língua formal do ambiente que as cerca; o segundo aspecto se reporta ao fenômeno amplo da criação dos clubes de leitura, ou de grupos de leitura. A amplitude do fenômeno, ou seja, o aumento de grupos/clubes de leitura indica que a própria literatura é um fenômeno social, e que na verdade é a razão do aparecimento e da existência desses grupos e também a causa de outras interações sociais. A dinâmica do grupo, por sua vez, promove a atuação e a contribuição no campo da análise literária.

A pesquisadora Joan Bessman Taylor comenta que quando um membro do grupo de leitura lê uma obra que foi por ele elegida, a consciência do debate esperado acompanha sua leitura e faz com que se relacione de modo diferente a determinados elementos do texto. Elementos que de outra forma sequer seriam percebidos saltam aos seus olhos e ganham mais tempo de observação e pensamento. Além disso, argumenta que a atividade social do grupo de leitura enriquece e amplia o método de análise de cada um dos membros, porque as tendências, a abordagem e o gosto pessoal de cada um influi no restante do grupo (TAYLOR, 2007).

Os membros do grupo não são escritores, pesquisadores ou críticos, trata-se de amantes da leitura, um grupo de pessoas que combinam seu prazer particular da leitura literária com uma atividade social. O leitor solitário, que anteriormente era um consumidor passivo de 
literatura, transforma-se em colaborador na análise da criação da obra. Será que isso o torna um transgressor, que invade o terreno alheio? Taylor argumenta que "a presença cada vez maior de clubes de leitura e as suas atividades, apontam para o fato dos leitores não mais transgredirem invadindo a ceara alheia, eles estão estabelecendo seu próprio espaço [...] e ao fazer isso, não estão distantes de serem eles mesmos, escritores. Os leitores dos clubes de leitura criam e plantam. Sua interatividade com outros leitores permite que outros colham o produto de sua experiência” (TAYLOR, 2007, p. 114).

Neste artigo traremos ideias e relações que foram levantadas pelo grupo sobre dois romances de autoria de Dorit Rabinyan: O beco da amendoeira em Omeridjan ${ }^{1}$ (1995), e Nossos casamentos ${ }^{2}(1999)$. Vamos tratar também do terceiro romance da autora, recémpublicado, o Cerca viva ${ }^{3}$ (2014).

Dorit Rabinyan nasceu em 1972, em Kfar Saba, Israel, com família é de origem persa. Além dos três romances mencionados acima, escreveu também o roteiro do filme $O$ rapaz de Shuli ${ }^{4}$, filmado sob a direção de Doron Tsabari e premiado em 1997 pela Academia Israelense de Cinema. Em 2006, publicou um livro infantil intitulado Então, onde eu estava? ${ }^{5}$.

O primeiro livro da autora foi publicado quando tinha 22 anos apenas, e logo se tornou best-seller, tendo sido traduzido para muitas línguas. Recebeu, por essa obra, o prêmio A jovem ficção, em nome de Ytsrrak e Tova Winer. Seu segundo romance fez muito sucesso, e por ele ganhou o prêmio em nome de Ord Wingate, em 1999, e, em 2000, o prêmio Primeiro Ministro, em nome de Levi Eshkol ${ }^{6}$.

$\mathrm{O}$ romance $O$ beco da amendoeira em Omeridjan nos leva ao mundo das mulheres que vivem no bairro judaico, em uma pequena aldeia na Pérsia do início do século XX. Trata-se de um mundo exótico e colorido, dominado por demônios, espíritos, maldições e magias, e por entre eles o judaísmo desponta de quando em quando.

O romance tem o caráter de saga, relatando a história de uma família, suas ramificações e suas gerações. A família nuclear do relato é Ratorian, formada por Miriam Rranum, seu marido açougueiro e seus três filhos, Mussa, Homa e Flora. Em sua casa vive Nazi, a sobrinha órfã que Miriam e o marido adotaram depois de seus pais terem morrido numa mesma noite,

\footnotetext{
${ }^{1}$ No original: סמטת השקדיות בעמריג'ן. Todos os títulos foram traduzidos por Eliana Langer.

2 החתונות שלנו 2

גדר חיה

הבחור של שולי 4

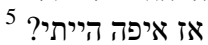

מתוך:"דורית רביניאן", אתר לקסיקון הספרות העברית החדשה, בעריכת חבר ספרנים6
} 
aparentemente por causa de uma gastroenterite. Quase esquecida dentro de uma pequena sesta num canto da sala, encontra-se a velha avó, mãe de seu pai, chamada Manijon.

A sociedade retratada no romance é patriarcal, cuja especificidade decorre do fato do patriarcado ser caracterizado pelo sexismo acompanhado de crueldade e apoiado pelo Estado muçulmano.

O controle sobre a sexualidade das mulheres dá aos homens a possibilidade de escolherem seus herdeiros e assim assegurarem a continuidade e a perpetuação de seu nome. Tal objetivo se transforma no valor central da honra que confere aos homens o direito de usar de violência contra as mulheres da família. Mussa bate em sua irmã Flora toda vez que ela circula pelas ruas e demora em voltar para casa, exigindo aos berros que seja discreta e pura e que possa comprovar isso sem deixar dúvidas: "Toda a aldeia virá amanhã pela manhã com as mulheres e crianças e passará pelos portões da sinagoga para olhar dentro do buraco de minha irmã e ver que ela é virgem!" (RABINYAN, 1995, p. 39). A mulher nessa sociedade é objeto; a fêmea é, decisiva e indubitavelmente, inferior ao macho. Portanto, o nascimento de uma filha provoca sofrimento e não alegria: "quando você me dará os machos que eu quero? [...] você só me dá meninas" (Ibid., p. 91), diz o pai de Nazi a sua esposa, e logo depois do parto a pune barbaramente por sua incapacidade de parir filhos machos.

A mulher ideal deve estar bela para o casamento, elegante e feminina, ainda que para isso deva sofrer. A mulher deve estar "preparada" para aguentar dor, pois deve trazer filhos ao mundo: "o que vai ser quando você se agachar para parir, Flora, quanto você vai gritar na hora de parir?" (Ibid., p. 53), diz a mulher que depila o corpo de Flora para o casamento. A noiva deve ser linda, boa dona de casa, fértil, mãe protetora que cuidará dos machos para serem homens fortes e merecedores de respeito, e das fêmeas para serem meninas dóceis, submissas, prestativas e lindas.

Contudo, as mulheres no romance são fortes e encontram meios de lutar, por vezes até o fim, para realizar seus desejos, os quais estão sempre ligados às suas funções tradicionais: amor, casamento ou procriação. Na verdade, essas lutas demonstram coragem, inconformismo e resistência ao preconceito social. No entanto, todos esses anseios objetivam o cumprimento e a preservação da ordem estabelecida e a divisão das funções tradicionais.

A seguir alguns exemplos: Nazi, a sobrinha órfã é aparentemente o protótipo e o símbolo da fraqueza feminina. É a quinta filha de sua mãe, pois todas as anteriores morreram 
logo ao nascer, sendo Nazi a única a sobreviver. É muito fraca, pequena e frágil, mas desde tenra idade desempenha bem seu trabalho diário, que é corporal e pesado.

Nazi, que nascera prematura, sobreviveu graças a sua mãe que lutou contra todas as probabilidades e contra todos os homens fortes e autoritários da aldeia, inclusive o médico e o marido, o pai de Nazi, que atirou fora o bebe doente numa noite em que nevava. Nazi é a concretização, na variação persa, do mito da Cinderela, que apesar de ser membro da família e dormir no mesmo quarto que as meninas da casa, é a serviçal que executa sozinha todo o trabalho da casa de sua tia, justificando assim a sua existência.

A força de Nazi alcança o ápice quando ela, a pequena judia, consegue que o Imam (líder religioso e estatal do império islâmico) lhe dê permissão de se casar apesar de ainda não ter menstruado.

Flora tem quinze anos e é uma menina mimada, muito bonita, atraente e exala sensualidade. Casou-se com Shahin, mascate ambulante, depois de ter recusado um respeitado arranjo matrimonial. A coragem desta recusa mostra o atrevimento, ou a tolice de quem não entende o quão difíceis podem ser as consequências de seus atos. Flora engravidou em uma noite de eclipse da lua, fato considerado um mau presságio no rico repertório de crendices da aldeia e, portanto, seu marido desapareceu pouco tempo depois. Flora, no entanto, não conseguindo aguentar as saudades dele e não estando pronta para aceitar seu destino, sai para uma longa viagem a fim de procurá-lo sozinha e carregando uma gestação adiantada.

Por fim, convém mencionar a figura especial de Miriam Rranum. A força da personagem se expressa na firme revolta contra um dos papéis tradicionais femininos: ela se recusa a desempenhar a função de dona de casa, e também ensina suas filhas a seguirem a nova tradição provocativa que começara. Miriam casou-se aos catorze anos com o filho do vendedor de galinhas. Em seu casamento, depois do noivo, emocionado, ter pisado em um copo e o quebrado, Miriam pisou no pé de seu marido. Os cacos de vidro se quebraram novamente e "o seu poder foi decretado" (Ibid., p. 18). Miriam reinava dentro de casa, era ela quem mandava. Seu marido era somente o provedor, e para enfatizar isso, o nome dele não é citado, apenas sua ocupação.

A origem de seus novos comportamentos está cravada na memória de sua remota infância. Sua mãe, Shirin, limpou a casa durante todo dia e quando, à noite, seu marido retornou e viu a casa limpa, cuspiu em sua cara. Quando ela lhe perguntou o que fizera de errado, ele lhe disse que precisava cuspir, e como a casa estava limpa e brilhando, enquanto 
ela estava vestida com trapos e com o corpo sujo por causa das muitas horas de trabalho, era o lugar mais adequado para o seu cuspe. A mãe ficou triste e ofendida e, desde aquele dia, não mais limpou e nem arrumou a casa, e Miriam aprendera isso com ela: deixar a casa para lá e cuidar de seu corpo e de seus filhos. A sociedade a sua volta não a vê com bons olhos, não aceita o fato da mulher não querer se submeter à casa, à cozinha, à limpeza, pois essa é sua função. Suas vizinhas a chamam de "a gata imunda", e todas tentavam ensiná-la o trabalho da dona de casa e se ofereceram para bater nela no lugar do seu "fraco marido e em nome de sua velha sogra" (Ibid., p. 19).

Por vezes, podemos perceber certa demonstração de fraternidade entre as mulheres, mas são solitárias em suas grandes e heroicas batalhas. Por exemplo, segredos do sexo passam pelo folclore feminino de mãe para filha. Antes da noite de núpcias, as mulheres mais velhas precisam explicar para as jovens noivas o que elas devem fazer durante a cópula com seu parceiro; transmitir a elas detalhes práticos sobre o comportamento na cama. É evidente que a orientação aponta para o propósito central: a procriação - de machos, de preferência! -. Apesar disso, o sexo permanece um assunto vago e obscuro e a falta de conhecimento leva a enganos, como no caso do marido virgem que casou com a vizinha Fatena e não consegue engravidá-la porque tenta introduzir seu membro no umbigo da moça.

A falta de conhecimento, provavelmente, contribui para a força e a importância das crendices e de sua prática. Por exemplo, o tratamento dado às estéreis, problema muito difícil para esta sociedade: “A mãe da estéril jogava dentro da cova quarenta copos de água, e esta água lavava o ventre cerrado da filha, enquanto pranteava na esperança de que seu útero se abrisse e ela procriasse muitos filhos" (Ibid., p. 81).

A duvidosa fraternidade feminina é também percebida em relação às mulheres idosas na história, as quais pertencem ao modo de vida social da aldeia e moram na casa da família. Em geral, na velhice são fracas e não muito levadas em consideração. Manidjun, a sogra de Miriam e mãe de seu marido, mora junto a eles na casa. Miriam a empurrou para um canto desde o primeiro momento, lhe trouxe um cesto de vime pequeno, adequado para o seu tamanho e, desde então, Manidjun quase não sai do cesto. Ela é descrita como uma pessoa desequilibrada, a quem ninguém dá atenção e tampouco o que diz é levado a sério. Mais uma vez temos a confirmação da posição rebaixada das mulheres, do nascimento à morte.

A exemplo de todas as sociedades tradicionais, aqui também as mulheres, e não os homens, tomam para si a responsabilidade de criar os filhos e cuidar da casa. No entanto, no 
romance isso é apresentado como uma vantagem para as mulheres, como ponto de poder e origem da força. Portanto, a mãe que age a favor de um filho se enche de uma força quase selvagem e não há quem a refreie. Na caracterização da figura dos homens, apesar da força física e da legitimação social que lhes permite ferir as mulheres de várias maneiras, a sensação é de que são excluídos e afastados do mundo das mulheres, da interação tão achegada com os filhos e de toda atividade ligada a realização das tradições e rituais familiares e sociais. No romance, as mulheres são levadas à frente e ao centro do palco.

O segundo Romance de Rabinyan, Harratunot Shelanu (1999) ${ }^{7}$, conta a história da família Azizian: o pai Soli e a mãe Iren, ambos novos imigrantes (ele da Turquia e ela da Pérsia), encontraram-se e se apaixonaram em Israel. O romance conta a história da família, sua vivência e seu florescimento; uma história que começa com o simples e forte amor entre os pais e continua com o nascimento dos cinco filhos: Moris o primogênito, e as quatro meninas que nasceram depois dele, as belas Sofia, Marcel e Lizi, e Mati. O irmão gêmeo de Mati morreu logo depois do nascimento.

O grande amor dos pais transforma o casamento numa ideia de concretização da felicidade e a história mais querida das filhas pequenas, a qual a mãe lhes conta repetidamente. É uma fantasia sobre o futuro casamento delas. Com a maturidade, a fantasia de cada uma se materializa por um breve instante, mas rapidamente se destroça. Tal situação faz com que Iren mergulhe na tristeza e na constante preocupação com seus filhos, dedicando suas energias e a maior parte de seu tempo a correr atrás de religiosos e rabinos na esperança de, talvez, neles encontrar a salvação. Iren acaba incluindo em sua preocupação toda a casa da família, acarretando assim o esfacelamento do amor e de seu casamento.

No grupo de leitura falamos sobre tipos de maternidade, e cunhamos o termo "Irenica" significando "maternidade total", mãe que aparentemente se dedica totalmente aos filhos, abdicando dela própria. Usamos o advérbio "aparentemente", pois, na verdade, Iren não apenas dá aos filhos, ela também tira deles; recebe deles a sua essência materna, já que sem eles ela não seria mãe. Todo o seu ser é maternidade. Será que essa mãe total, da qual talvez em todas nós mulheres existe algo, de mãe provedora e nutridora se transforma em mãe que sufoca e castra? Yehudit Shiran tem uma resposta decisiva para a questão: "não há dúvidas que Iren se doou plenamente aos filhos, e, no entanto, ela é aquela mãe que não possibilita o crescimento e o florescimento que promovem amadurecimento, a mudança espiritual e o

\footnotetext{
${ }^{7}$ Nossos casamentos, em português.
} 
alcance de autonomia física e, assim, ela se transforma em uma mãe má” (SHIRON, 2015). Isto é expresso de forma muito clara na história pelo fato de todos os filhos de Iren serem estéreis, ao menos metaforicamente. Não procriam, permanecem solteiros (Moris), divorciados (Marcel) ou na gravidez imaginária (Lizi). A única que procria um filho é Sofia, porém seu bebê frágil e doentio é um fruto "defeituoso", nascido de um ventre árido.

A bela Sofia casa-se com Itsik Kadosh, que enriquecerá fazendo importação de joias de ouro ocas. Essas joias simbolizam a essência da própria Sofia: tudo em sua vida é oco, e ela é apenas uma bela casca que cobre um vazio, nada há em seu interior.

No comportamento sexual de Lizi, a ninfomaníaca, há algo simbólico. Sua forte atração pelo próprio corpo, a masturbação, é análoga a sua gravidez imaginária: é a esterilidade de quem é apaixonado apenas por si mesmo, tanto física como sexualmente. A sexualidade de Lizi é autônoma, autárquica, pois ela necessita apenas dela mesmo. Seu comportamento ninfomaníaco comprova justamente a impossibilidade dela encontrar satisfação na relação com homens. Daí sua obsessão insaciável - pois ela nunca se satisfaz. Isto explica também a surdez de Lizi. Não se trata de uma surdez patológica, trata-se de uma surdez que ela própria provoca como meio de se fechar em uma bolha e se desligar de tudo que a rodeia. Ela é um tipo de andrógina que pode e quer copular apenas consigo próprio.

Marcel, criando para si um mundo baseado em livros românticos e filmes de amor, se parece com Sofia. Tais livros e filmes representam uma espécie de casca vazia, ou seja, uma beleza externa e brilhante e nada mais, pois é totalmente desligado da realidade, sem nenhum sentido ou conteúdo ligado à vida concreta. Seu único sentido é a completude romântica dela própria. Portanto, suas aspirações são vazias e estéreis exatamente como a gravidez imaginária de Lizi. A elas falta concretude.

A impotência e, é claro, a solidão de Moris são totalmente freudianos: trata-se de um caso "clássico" de filho apaixonado pela mãe, que, por sua vez, ao incentivar a ligação especial dela com ele, o castra.

A loucura e o isolamento de Mati estão no fato dela viver no limite entre dois mundos o dos vivos e o dos mortos. Ela lembra o motivo universal da noiva casada com um homem morto, pois ela se sente ligada totalmente a seu irmão gêmeo, Moni, que morreu ao nascer ${ }^{8}$. Enquanto Moni faz parte da existência de Mati, se parecendo e se comportando como uma

\footnotetext{
${ }^{8}$ Um bom exemplo para esse motivo é possível encontrar no poema de Alterman, $O$ estranho inveja a graça da noiva (Anexo 1).
} 
louca, ao mesmo tempo é uma criatura que carrega a completude de duas: do macho e da fêmea, como na definição de amor de Platão ou, ainda, uma variante do amor sexual de Lizi.

Enfim, cada um dos filhos de Iren tem um defeito que o desliga do mundo que o cerca, o arrebata e o impede de desenvolver-se em um ente completo capaz de agir e criar ligações concretas fora do âmbito familiar e fora da moradia da família. Todos, mesmo as filhas casadas, voltam à casa dos pais, ou nunca a deixam, como Moris. Não conseguem se desligar do passado e de sua infância. Seus casamentos, a fantasia infantil em comum, não se concretizam ou fracassam, pois os filhos ainda pertencem à Iren e à casa da família. Não se tornaram independentes, não cortaram o cordão umbilical. A ligação de Iren com os filhos é física, complexa e forte, de forma que torna difícil separar um corpo do outro, uma entidade da outra: "a mãe e Moris eram tão próximos um do outro, como marido e mulher" (RABINYAN, 1999, p. 52) e ela e suas filhas enroscadas umas nas outras como "os galhos da buganvília ardente" (Ibid., 161). A existência e a definição de autonomia: questão central de todos os membros da família no romance.

Os processos de maturação e de separação se dão no final da história, nos quais observamos dois eixos paralelos. Quando Mati, a mais jovem das irmãs, provoca a separação entre ela e seu irmão gêmeo morto, suas três irmãs mais velhas provocam a separação entre elas e a mãe. As filhas mais velhas expressam isso quando explicam a Iren que a vida delas não lhe pertence e, portanto, suas dores, seus problemas e suas preocupações não são da mãe que não precisa, e também não pode lutar as batalhas das filhas. Os dois lados compreendem e isso permite que elas passem por um processo terapêutico que é expresso simbolicamente pela limpeza da casa. A limpeza e a ordem da casa simbolizam a limpeza e a ordem da alma (a cura). Ao mesmo tempo, Mati se esconde fora da casa e tenta cortar o pescoço com uma tesoura. Em um primeiro momento, temos a impressão de que o ato é uma tentativa de suicídio. Mas, ao entendermos a necessidade de cada um da família se separar do "nós", da entidade comum para poder crescer, desenvolver-se e se tornar um indivíduo independente, que possa viver uma vida concreta e criar novos vínculos saudáveis, passamos a entender também a atitude de Mati não como uma tentativa de suicídio, mas como uma separação de Moni. Ela "mata" Moni; corta a amarra que os ata para poder se curar, ou seja, poder viver e se desenvolver como uma pessoa completa. 
O terceiro e mais recente romance de Rabinyian é Gader Rrayá (RABINYAN, 2014) ${ }^{9}$, acontece em Nova York no início dos anos 2000. À época começaram a construir em Israel o "muro da separação" e sua relação com o título do romance o leitor percebe logo de início. É a história de amor entre Liat, tradutora israelense que recebera uma bolsa para trabalhar em Nova York durante um semestre, e Rrilmi, um jovem palestino, pintor talentoso que recebera um visto de artista por quatro anos. Eles se conhecem por intermédio de um conhecido em comum em um café de Nova York e, dessa noite até o retorno de Liat a Israel, não mais se separam. Para Liat está claro que, apesar de seu profundo amor por Rrilmi, esse relacionamento é temporário e terá que se encerrar com o seu retorno para Israel. Rrilmi é mais moderado do que ela, e não pensa que a relação amorosa entre uma israelense e um palestino seja impossível. Suas abordagens distintas acerca do relacionamento entre eles são análogas às suas posições políticas: "Rrilmi é mais conciliador. Liat apoia a criação de dois estados para dois povos que viverão lado a lado, cada qual em seu lugar, enquanto que Rrilmi pensa que não haverá como fugir da solução de um estado binacional, e que tanto árabes como israelenses serão obrigados no final das contas misturar-se uns com os outros e se acomodar com o que se lhes é oferecido" (DORIT, 2014, p. 46). Esse romance não foi tratado no grupo de leitura e, portanto, trataremos dele brevemente, apontando apenas dois assuntos interessantes.

Começaremos pela alegoria relacionada aos nomes do par de heróis: Liat, a narradora israelense, representa pelo seu nome a origem e, na verdade, a essência do conflito entre israelenses e palestinos: "li" "at" - "você é minha"; este é o argumento de ambos os lados em relação a Terra de Israel. Os dois povos reivindicam seus direitos sobre a mesma terra, o mesmo Estado. Assim, Liat é o "corpo" do desentendimento, e também se divide entre o amor por Rrilmi, o palestino, e o amor de seus pais. Para ela está claro que não há um acordo possível entre os dois.

Rrilmi ("sonho", em árabe), o palestino, é um pintor e, conforme seu nome, desenha muitos quadros de um jovem sonhador que perambula ou paira sobre a terra de olhos cerrados. O jovem desenhado é a imagem dele próprio, e em seus desenhos há uma variedade de tons de verde e azul - cores calmas. Na figura de Rrilmi há algo de devaneio e de suavidade. É um artista em todo seu ser e, portanto, a "situação", ou seja, o conflito e a violência, não o atingem. Portanto, ele consegue criar uma arte que não é engajada e sem

\footnotetext{
${ }^{9}$ A cerca viva (o muro vivo).
} 
nenhum tom político. Ele desenha um jovem sonhador que flutua, vagueia ou anda sobre as águas de olhos cerrados. Sua arte desenha algo desligado da realidade, e esse desligamento o faz crescer para além dela, pois ele é o único que pode passar por cima da realidade e das rixas, dos ódios e dos desentendimentos de longa data: a razão pela qual Rrilmi tem que morrer. Sua natureza sonhadora sugere uma possibilidade de ir além do conflito; ver a beleza além dele, ou a beleza existente apesar do medo e do ódio. Contudo, a realidade é mais forte do que qualquer sonho e sonhador. A realidade, como se costuma dizer, vem e nos bate na cara; e o mar cruel, que Rrilmi tanto gostava de pintar, o engoliu.

Por que você escolheu chamar o livro de "cerca viva"? Perguntaram a Dorit Rabinyan em uma entrevista ao jornal Haarets (SELA, 2014). Sua resposta foi: "porque esclarece bem o tema dos limites que é o elemento central da história, como isso vive dentro de nós, as cercas conscientes, físicas, concretas, fictícias. E também porque essa expressão, "cerca viva", de repente me fez ouvir a tensão dramática, o perigo que a espreita. Um limite onde não há segurança, onde jamais há prazer, que de repente pode se mover ou se erguer contra você ou desaparecer."

No final da história, Rrilmi morre, mas a cerca ainda vive. Essa é mais uma maneira de expressar a sensação de que as pessoas nascerão e morrerão, gerações virão e irão e a disputa ainda estará encravada profundamente na terra de Israel. A cerca vive ainda dentro de Liat, que é incapaz de atravessá-la, transpor os tabus não lavrados da sociedade e da cultura em que crescera e na qual resta a separação de dois povos entre os quais a vida criou, em um mesmo território, uma cerca de medo e ódio.

Nos três romances de Dorit Rabinyan, podemos perceber duas linhas de desenvolvimento ligadas uma à outra. Paralelamente ao ritmo cronológico, se dá uma aproximação geográfica da história que acontece: "era uma vez" e "lá" - O beco das amendoeiras, na Pérsia do início do século XX; Nossos casamentos, a história que acontece no decorrer da segunda metade do século, em Israel; e, finalmente, o romance Cerca viva, que acontece em Nova York e em Israel, no início do século XXI.

A segunda linha de desenvolvimento pode ser descrita como o movimento de passagem do geral ao particular ${ }^{10}$, que talvez seja um processo gradual de ousadia; chegar cada vez mais e mais perto do "eu" pessoal: O beco das amendoeiras em Omaridjan, trata da situação das

\footnotetext{
${ }^{10}$ Grosso modo, este é o processo paralelo ao que viveu e ainda vive a sociedade israelense, processo em que a exigência do engajamento do indivíduo em tarefas sociais vai gradativamente sendo substituída pela legitimação dos desejos pessoais no topo da escala de preferência.
} 
mulheres na sociedade como um todo, representada pela aldeia. Rabinyan documenta isso dizendo: "no primeiro romance, um pouco como mediúnica, sem ter consciência, contei a lembrança de minhas avós, minhas mães e minhas tias. Servi de boca para dar voz a uma geração feminina calada. Personifiquei-as em hebraico. Na verdade com o meu hebraico eu redimi a história delas." Nossos casamentos focaliza um caso específico de uma família nuclear. O círculo "geral”, apesar de se encolher, não se desfaz em partes isoladas. A família inteira é o narrador, cuja voz múltipla é escutada por meio de um "nós". Em Cerca viva o "nós” não apenas passa para o "eu”, o narrador em primeira pessoa do singular, mas a figura da narradora se desliga de sua família por meio de sua permanência temporária em outro país. O afastamento é necessário para examinar o indivíduo desligado do coletivo.

A passagem gradativa de gênero do fantástico para o realístico também demonstra o amadurecimento da escritora para contar o pessoal, o particular verdadeiro e doloroso.

\section{Referências}


MALIK-SHIRAN, Y. Como a literatura fantástica se expressa em "Nossos casamentos". Disponivel em: <cms.education.gov.il>. Acesso em: 3 set. 2015.

SELA, M. Dorit Rabinyan revela porque se calou durante 15 anos. Haaretz, Caderno de Literatura, 30 maio 2014.NESTELBAUM-GAZ, Maya. Dorit Rabinyan: a falta de realização artística se torna paralisia. Disponível em: <http://www.globes.co.il>. Acesso em: 1 jun. 2011.

TAYLOR, J. B. When adults talk in circles; Book groups and contemporary Reading practices. 2007, 114f. Tese (Doutorado) - Illinois University. 


\section{Anexo 1}

הזר מקנא לחן רעייתו / נתן אלתרמן

O forasteiro cobiça a graça da esposa ${ }^{11}$

\begin{tabular}{|c|c|}
\hline Não vistas a roupa de festa & אל תלבשי את שמלת \\
\hline Não rias jamais & החג - - - - - - - - 1 \\
\hline Ele irá te bajular e seduzir e falar & אל תצחקי לעולם \\
\hline E eu giro em torno de ti & מסביבך יחנף ויפתה וילהג \\
\hline E eu como uma águia giro e te & ואני מעגל עולמים לך חג \\
\hline espero & ואני על קוו כמו עיט חג \\
\hline Te resgato dos filhos de rram e te & ממלטך מבני חם ונוצרך \\
\hline guardo & מקהלם \\
\hline Para que não vejas o sol e não & לבל תראי שמש לבל תדעי \\
\hline festejes & תג \\
\hline E não rias jamais & לבל תצחקי לעולם \\
\hline Se fugires para um canto secreto & אם תנוסי אל סתר בית \\
\hline da casa & אם בשבת רעים תשטי \\
\hline Se folgares na companhia de & לא תנוסי מקול העיט \\
\hline amigos & המצעק לך אשתי אשתי \\
\hline \multicolumn{2}{|l|}{ Não fugirás da voz da águia } \\
\hline Que clama por ti minha mulher & אל גובה מתנייך ויקר רגלך \\
\hline \multirow[t]{2}{*}{ minha mulher } & מי עפר יגלה מעיני \\
\hline & כמו נר אלווך וכאויב ארגלך \\
\hline À altura de sua cintura e seu & כי שלי את כולך כולך כולך \\
\hline precioso pé & בחזיז צפורנייך ובגץ עגילך \\
\hline Quem dera meus olhos & ורואייך שונאי וחובך מעוני \\
\hline empoeirados vissem & ונבקע העפר בו תדרוך רגלך \\
\hline Feito vela acompanhar-te-ei e & ובקעו מעפר עיני \\
\hline feito inimigo assombrar-te-ei & \\
\hline Pois tu és toda toda toda minha & ובלכתך אל משכב בשניים \\
\hline
\end{tabular}

${ }^{11}$ Tradução: Eliana Rosa Langer. 


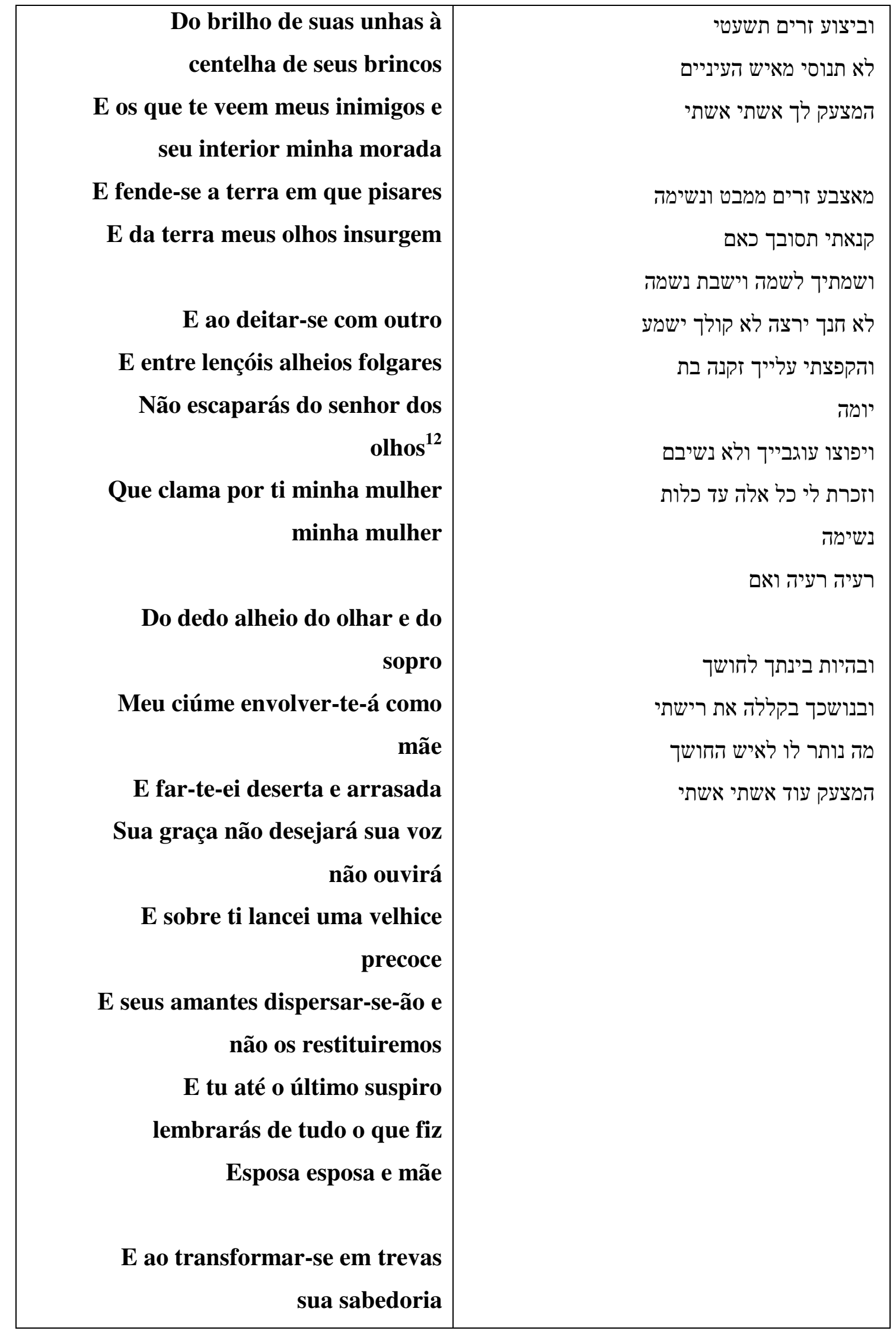

${ }^{12}$ Alusão ao Anjo da Morte que na cultura judaica possui muitos olhos (EZEQUIEL, 1:18). 


\begin{tabular}{|r|r|}
\hline E ao morderes praguejando & minha rede \\
O que resta ao homem das trevas & \\
Que ainda clama minha mulher & minha mulher
\end{tabular}

